\title{
Effect of Chronic Morphine Consumption on Synaptic Plasticity of Rat's Hippocampus: A Transmission Electron Microscopy Study
}

\author{
Mohammad Hassan Heidari, ${ }^{1}$ Abdollah Amini, ${ }^{1}$ Zohreh Bahrami, ${ }^{1}$ Ali Shahriari, ${ }^{2}$ \\ Abolfazle Movafag, ${ }^{3}$ and Reihane Heidari ${ }^{2}$ \\ ${ }^{1}$ Department of Biology and Anatomical Sciences, Faculty of Medicine, Shahid Beheshti University of Medical Sciences, Tehran, Iran \\ ${ }^{2}$ Department of Anesthesiology, Roozbeh Hospital, Tehran University of Medical Sciences, P.O. Box 1417653761, Tehran, Iran \\ ${ }^{3}$ Department of Genetic Science, Medical Faculty, Shahid Beheshti University of Medical Sciences, Tehran, Iran
}

Correspondence should be addressed to Ali Shahriari; kowsarkavosh@gmail.com

Received 18 August 2013; Revised 27 September 2013; Accepted 29 September 2013

Academic Editor: Di Lazzaro Vincenzo

Copyright (C) 2013 Mohammad Hassan Heidari et al. This is an open access article distributed under the Creative Commons Attribution License, which permits unrestricted use, distribution, and reproduction in any medium, provided the original work is properly cited.

\begin{abstract}
It is well known that the synapses undergo some changes in the brain during the course of normal life and under certain pathological or experimental circumstances. One of the main goals of numerous researchers has been to find the reasons for these structural changes. In the present study, we investigated the effects of chronic morphine consumption on synaptic plasticity, postsynaptic density thickness, and synaptic curvatures of hippocampus CA1 area of rats. So for reaching these goals, $24 \mathrm{~N}$-Mary male rats were randomly divided into three groups, morphine $(n=8)$, placebo $(n=8)$, and control $(n=8)$ groups. In the morphine group, complex of morphine $(0.1,0.2,0.3$, and 0.4$) \mathrm{mg} / \mathrm{mL}$ and in the placebo (sucrose) group complex of sucrose (\% 0.3) were used for 21 days. After the end of drug treatment the animals were scarified and perfused intracardinally and finally the CA1 hippocampal samples were taken for ultrastructural studies, and then the obtained data were analyzed by SPSS and one-way analysis of variance. Our data indicated that synaptic numbers per $\mathrm{nm}^{3}$ change significantly in morphine group compared to the other two groups (placebo and control) $(P<0.001)$ and also statistical analysis revealed a significant difference between groups in terms of thickness of postsynaptic density $(P<0.001)$ and synaptic curvature $(P<0.007)$. It seems that morphine dependence in rats plays a main role in the ultrastructural changes of hippocampus.
\end{abstract}

\section{Introduction}

Today the opiates are the most addictive substance used in the world wide and they are considered as one of the greatest neuropsychological disorder reasons [1-4]. It has been shown that chronic consumption of opiates can significantly change the functions, structures, and morphology of neural systems $[5,6]$. This kind of changes causes several different types of disorders such as drug addiction, carelessness, fluent speech disorders, memory and learning impairment, and psychological disorders [7-10].

According to the studies, drug addiction is an abnormal form of learning and an adaptation of the memory system in certain regions of the brain, such as the hippocampus [11].
The learning processes are defined as a modification in some synaptic functions (synaptic plasticity), changes in the preand postsynaptic ultrastructure, and the formation of new synapses $[10,12]$. It is known that the synapses of hippocampus formation are more structurally affected by learning process [12-16]. There are previous researchers demonstrate that opiates have either direct or indirect effect on capacity of learning and memory, processes. Concerning the role of the hippocampal synapses in learning, memory, and circuit reward process, it was concluded that morphine consumption as a main opiate substance can cause some functional, structural, and morphological changes in synapses of the hippocampus in the mammalians $[17,18]$. 
However, many works support the link between synaptic plasticity changes and repeated morphine consumptions but only a few studies have recently start to examine the ultrastructural effects of morphine on synapses to explain the relationship between altered connectivity and opiate treatment $[4,19]$. So to look into these issues with more details, the current experimental study employed transmission electron microscopy to compare the effects of morphine consumption on synaptic plasticity, postsynaptic density thickness, and synaptic curvatures in CA1 area of hippocampus formations.

The electron microscopy studies could provide some important evidence of synaptic plasticity and the precise pattern of synaptic restructuring.

\section{Method}

2.1. Experimental Animals. $24 \mathrm{~N}$-Mary male rats, weighing 290-300 g and 8-9 weeks of age, were used in this study. They were housed 4 per cage in a climate-controlled room under a 12-hour alternating light/dark cycle at a controlled temperature of $23 \pm 1$. Dry food pellets and water were provided ad libitum.

2.2. Drug. Morphine was purchased from the Darou Pakhsh Pharma Chem company in powder form. Then it was dissolved in tap water to produce solutions of $0.1,0.2,0.3$, and $0.4 \mathrm{mg} / \mathrm{mL}(\mathrm{w} / \mathrm{v})$. We dissolved 3 gram of sucrose per $100 \mathrm{~mL}$ of solution to reach a sweet solution.

2.3. Treatment. After 2 weeks of acclimation to the diet and the environment, $24 \mathrm{~N}$-Mary male rats were randomly divided into 3 groups, morphine $(n=8)$, placebo (sucrose) $(n=8)$, and control (water) $(n=8)$ groups. The rats in the morphine groups chronically consumed morphine solutions at doses of $0.1,0.2$, and $0.3 \mathrm{mg} / \mathrm{mL}$ for $48 \mathrm{hrs}$ and $0.4 \mathrm{mg} / \mathrm{mL}$ up to 21 days. Sucrose $(3 \mathrm{~g} / 100 \mathrm{~mL})$ was added to drinking water to mask the bitter taste of morphine. In the placebo group sucrose ( 3 g per $100 \mathrm{~mL}$ ) was administrated in drinking water for the same duration of time [10]. In the pilot study, the average water consumption during the administration of the highest dose $(0.4 \mathrm{mg} / \mathrm{mL})$ was $50 \mathrm{mg} \cdot \mathrm{kg}^{-1} \cdot$ day $[20,21]$.

2.4. Electron Microscopy Tissue Preparation. At the end of each drug treatment, all of the rats were deeply anesthetized with $100 \mathrm{mg} / \mathrm{kg}$ of pentobarbital and perfused transcardially with $4 \%$ paraformaldehyde $/ 0.6 \%$ glutaraldehyde in $0.1 \mathrm{M}$ phosphate, $\mathrm{pH}$ 7.4. Then, their brains were separated by usual dissection methods and postfixed in 4\% paraformaldehyde for $2 \mathrm{~h}$. After fixation, the samples were washed with PBS, then postfixed with $1 \%$ osmium tetroxide for $1.5 \mathrm{~h}$, again washed in PBS, dehydrated in an acetone series, and then embedded in epoxy resin [22-24].

For ultrathin sections the block face was first trimmed and the semithin sections were provided at $500 \mathrm{~nm}$ thicknesses, stained with $1 \%$ toluidine blue, and were examined by light microscopy, for finding the desired area. After finding desired area ultrathin sections ( $70 \mathrm{~nm}$-thick) were cut by ultramicrotome (ultracut UCT) with glass knives (Leica EMKMR2) at a thickness of silver-gold interface color and picked up on 100 mesh copper grids. The sections were stained with a $2 \%$ aqueous solution of uranyl acetate for $3 \mathrm{~min}$ and then with a lead citrate $(0.5 \%)$ solution for $5-10 \mathrm{~min}$. Ultimately, the samples were viewed on transmission electron microscope (Zeiss EM900) and micrographs were taken at $30,000 \mathrm{x}$ magnification. We tried to obtain uniform section thickness at the time of cutting.

2.5. Synapse Density. Synapse density was estimated by the dissector method. Eight electron micrographs were taken from three separate regions of each brain (24 micrographs per brain) at a magnification of $30,000 x$ on a Zeiss EM900 transmission electron microscope at $80 \mathrm{kv}$ (three "reference" planes). Here, the landmarks used to identify the correct location in each section typically consisted of cross sections of small myelinated fibers and clusters of mitochondria transversing the section. Images were stored and analyzed by an observer blind to group assignment.

The observer counted all of the synapses in the hippocampal sections and the physical dissector method was again used to calculate the synapse density, for which the number of synapses present in the reference section and not the look-up section was counted $\left(Q_{\text {synapse }}\right)$.

The total number of synapses within an unbiased counting frame of a known area $\left(A_{\text {frame }}\right)$ was counted $\left(1620 \mu \mathrm{m}^{2}\right.$ per brain at 50,000x for the ultrathin sections). Again, the dissector volume of tissue $\left(V_{\text {dis }}\right)$ is calculated using the formula from above, where $\mathrm{H}$ is section thickness $(70 \mathrm{~nm})$ multiplied by the number of sections. Synapse density, $N_{\text {vsynapse }}$, was calculated using the following formula: $N_{\text {vsynapse }}=Q_{\text {synaps }} / V_{\text {dis }}$ (using ultrathin sections).

2.6. Synaptic Ultrastructure. Synaptic ultrastructure, including thickness of postsynaptic density (thickest part), and synaptic curvature were measured by transmission electromicroscopic methods [10].

2.7. Statistical Analysis. Data were analyzed using SPSS software. One-way analysis of variance was used for synaptic density comparisons. $P<0.05$ was considered statistically significant.

\section{Results}

Analysis using the dissector methods showed a significant increase in the mean synaptic number per $\mu \mathrm{m}^{3}$ in hippocampus of morphine treated groups ( 1.85 synapse per $\left.\mu \mathrm{m}^{3}\right)$ compared to placebo ( 0.8 synapse per $\left.\mu \mathrm{m}^{3}\right)$ and control $(0.67$ synapse per $\left.\mu \mathrm{m}^{3}\right)$ groups $(P<0.0001)$. It reflects a positive significant relationship between synaptic density increases and morphine consumption $(P<0.0001)$. There was not any significant difference between placebo and control groups $(P<0.585)$. Here, the $95 \%$ confidence intervals for morphine groups, placebo, and control groups were 2.0930-1.6069, (0.9293-0.6706), and (0.8209-0.5910), respectively (Table 1). 


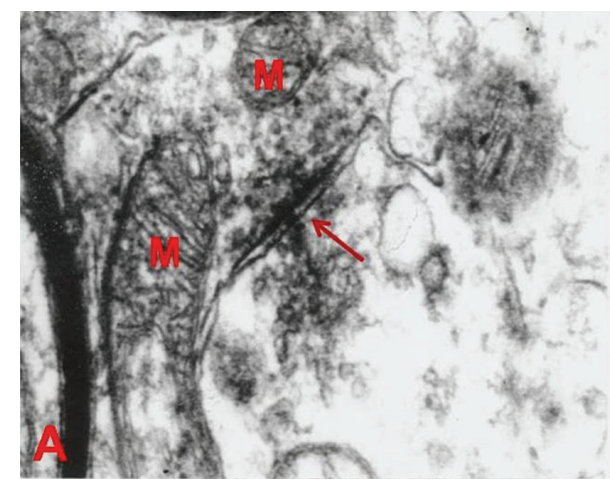

(a)

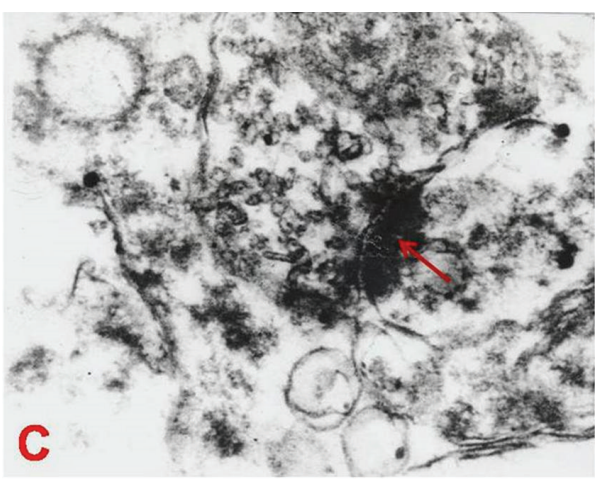

(c)

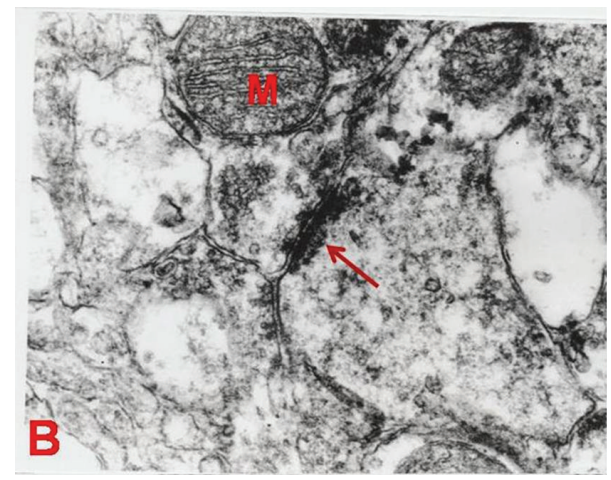

(b)

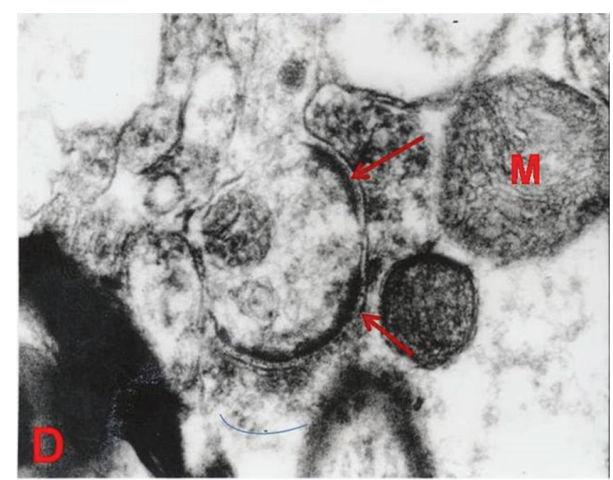

(d)

Figure 1: Electron microscopy of CA1 area of hippocampus: (a) control, (b) placebo group, and (c) and (d) morphine treated group (magnification: $\times 50000$, scale bar: $0.5 \mu \mathrm{m}$ ).

TABLE 1: Changes in synaptic number in the morphine treated group.

\begin{tabular}{lccc}
\hline Groups & $\begin{array}{c}\text { Synaptic } \\
\text { density per } \\
1 \times \mu \mathrm{m}^{3}\end{array}$ & $\begin{array}{c}95 \% \\
\text { confidence } \\
\text { interval }\end{array}$ & $P$ value \\
\hline Morphine & 1.85 & $2.0930-1.6069$ & $P<0.0001$ \\
Placebo (sucrose) & 0.8 & $0.9293-0.6706$ & \\
Control & 0.67 & $0.8209-0.5910$ & \\
\hline
\end{tabular}

3.1. The Changes of Synaptic Curvature (SCZ) between the Three Groups (Morphine, Placebo, and Control Groups) (Table 2 and Figures 1 and 2). As shown in Table 2, the analysis of hippocampal synaptic curvatures in rats that received morphine revealed a significant increase in the convex form of synapse (87.5\%) compared to those of placebo $(19.5 \%)$ and control groups $(12.5 \%)(P<0.0070)$. Here the concave form of synapses in morphine groups makes only $12.5 \%$ of all synapses compared to those of control (45\%) and placebo groups (39\%).

3.2. The Changes of Postsynaptic Thickness between Morphine, Placebo, and Control Groups. The statistical analysis also revealed a significant difference between groups in terms of thickness of postsynaptic density. As shown in the table below the minimum and maximum mean of thickness in morphine groups were $3 \mathrm{~nm}$ and $5.7 \mathrm{~nm}$, respectively ( $\mathrm{SD}=1.6$ and
$F=20.37)$. These results compared to those of placebo and control groups show significant increases in thicknesses of postsynaptic density $(P<0.0001)$. See Table 3 and Figures 1 and 2.

As shown in Figure 1, the synaptic contact zone curvature membrane is mostly convex in morphine groups (see the arrows in Figures 1, 2(c), and 2(d)) relative to control (see Figures 1 and 2(a)) and placebo groups (see Figures 1 and 2(b)). $M$ indicates the mitochondria.

As shown in Figure 2, Postsynaptic density (PSD) is thick in morphine groups (see arrows in Figures 2(c) and 2(d)) relative to control (see Figure 2(a)) and placebo groups (see Figure 2(b)).

\section{Discussion}

The aims of our present study were to determine the chronic effects of morphine consumption on synaptic number, the synaptic curvature, and synaptic thickness of the rat hippocampus.

Analysis of our present data showed that chronic consumption of morphine has positive effects on the number of synapse in rat's hippocampus. In other words, the consumption of morphine for a long time causes a significant increase in the total number of synapses (synaptic density) in hippocampal CA1 area in rats. These results are in agreement with those of Kauer and Malenka in 2007, Kelley in 2004, 


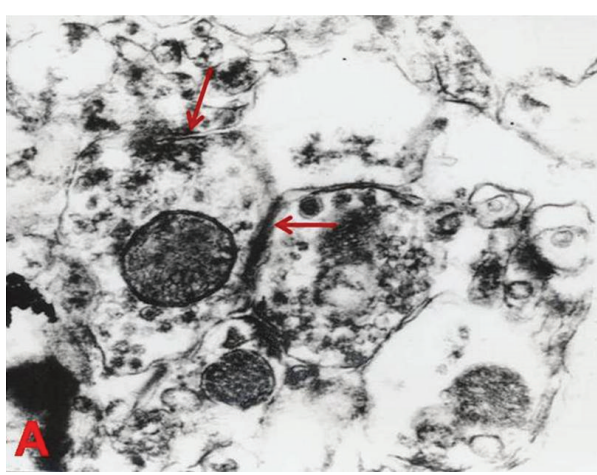

(a)

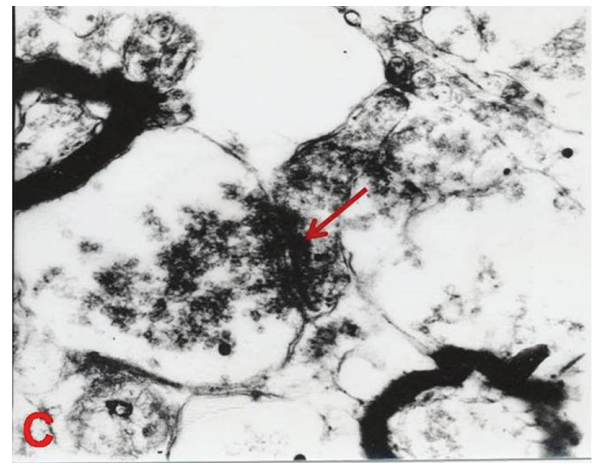

(c)

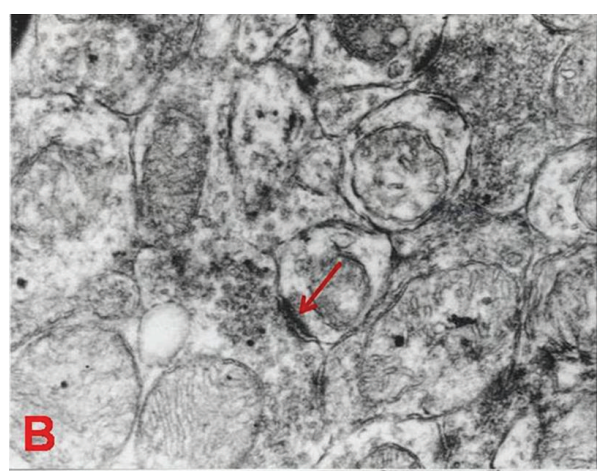

(b)

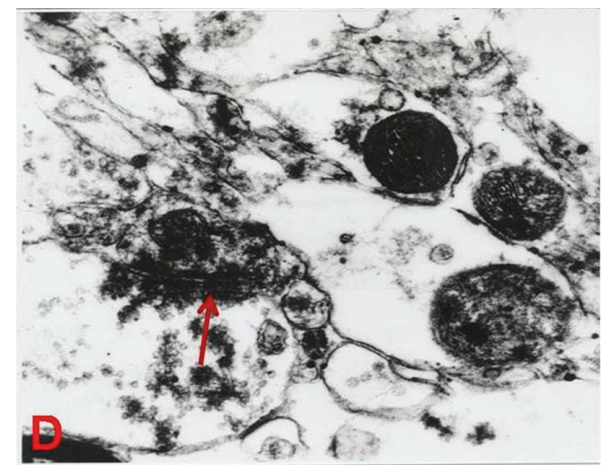

(d)

FIGURE 2: Electron microscopy of CA1 area of hippocampus: (a) control, (b) placebo group, and (c) and (d) morphine treated group (magnification: $\times 30000$, scale bar: $0.5 \mu \mathrm{m}$ ).

TABLE 2: The changes of synaptic curvature (SCZ) between the three groups (morphine, placebo, and control groups).

\begin{tabular}{lcccc}
\hline Groups & & \multicolumn{3}{c}{ Synaptic curvatures } \\
Concave form & Flat (no changes) & 0 \\
\hline Morphine & $N$ & Convex form & $12.5 \%$ & $0 \%$ \\
Placebo (sucrose) & 8 & $19.5 \%$ & $39 \%$ & $41.5 \%$ \\
Control & 8 & $12.5 \%$ & $45 \%$ & $42.5 \%$ \\
\hline
\end{tabular}

TABLE 3: Changes in thickness of postsynaptic density $(\mathrm{nm})$ in the studied groups.

\begin{tabular}{lcccccc}
\hline Groups & $N$ & $X$ & SD & SE & 95\% Confidence Interval & $F$ \\
\hline Morphine & 8 & 4.37 & 1.6 & 0.565 & $3-5.7$ & $P$ \\
Placebo (Sucrose) & 8 & 1.5 & 0.53 & 0.189 & $1-1.9$ & 20.37 \\
Control & 8 & 1.37 & 0.74 & 0.263 & $0.75-2$ & $P<0.001$ \\
\hline
\end{tabular}

and Berke and Hyman 2000 and Vorel et al. 2001 findings $[10,16,20,21]$.

They reported that synaptic plasticity is essential for neuroadaptations that resulted from a wide range of environmental stimuli. They also stated that use of the morphine, as environmental stimuli, for a long time can cause longterm changes in behavior by altering the synaptic structure, function, and number of synapses (the synaptic plasticity) in relevant brain circuits [10]. And also Alcantara et al. in 2011 and Pattij et al. in 2009 showed that morphine causes behavioral changes in animals. These morphine-induced behavioral changes are due to high sensitization of neuron to morphine consumption and changes in the number, function, and structure of synapse $[4,25]$.

It is thought that the structural and morphological changes of synapses, generation of new synapses, and synaptic plasticity have a main role in normal learning and memory process [14]. These findings suggested immediately that these processes are similar to associative learning and are essential in the early development of addiction.

In this study, an overall increase in the synaptic contact zone curvature was observed in the CAl area of hippocampus of morphine-treated animals. According to Medvedev et al. in 2010 and Connor et al. in 2006, the synapses curvature 
was classified as follows: concave, a protrusion of presynaptic terminal into the postsynaptic button; convex, a protrusion of postsynaptic button into the pre-synaptic terminal; flat, no discernable curvature $[26,27]$.

The increase in synaptic contact zone curvature in our work was mostly convex, a protrusion of postsynaptic button into the pre-synaptic terminal, in morphine groups relative to placebo and control groups. This finding is in agreement with Agnihotri, Suzuki reports [27, 28]. According to them, the curvature of synaptic membrane changes equally during normal development either as convex or concave, but this change in curvature of synaptic membrane in morphine treated groups was mostly convex. These show that morphine dependence may cause unusual changes in cytoskeleton structure of postsynaptic contact zones of dendritic spines of neurons [29].

And also our data showed that the postsynaptic thicknesses change in morphine treated groups compared to other groups (placebo and control groups). It has been reported that the changes in postsynaptic density thicknesses have a close relationship to the alteration of protein profile, cytoskeletal, and morphology of postsynaptic site. According to the literatures, the postsynaptic density (PSD) refers to the concentration of protein components in postsynaptic site, including signaling, receptors, and scaffold protein; these proteins receive and transduce synaptic information [30, 31].

According to the reports, it was concluded the postsynaptic density plays an important role in synaptic regulation and plasticity [32-36]. It also has been reported that the levels of these proteins are strongly influenced by several environmental factors, such as opiate drugs. For example, the repeated administration of morphine induced significant changes in the levels of postsynaptic proteins $[32,36,37]$ In one of the studies, Morón et al. 2007 [32] examined the levels of protein expression in synaptic membranes obtained from mouse hippocampus upon morphine administration using ICAT technology. They found that chronic morphine exposure induced an increase in the levels of proteins in postsynaptic site. Referring to the above results, the changes of synaptic curvature (SCZ) between the three groups (morphine, placebo, and control groups) it is likely has been shown that chronic consumption of opiates can significantly change the functions, structures, and morphology of neural systems, so it is likely that the increase of postsynaptic protein levels may cause a significant increase in postsynaptic density thicknesses as indicated by transmission electron microscopy in our experimental study. It is concluded that chronic morphine consumption plays a main role in the ultrastructural changes and synaptic plasticity in rats.

\section{Acknowledgment}

This study was supported by the Vice Chancellor for Research of Shahid Beheshti Faculty of Medicine, Shahid Beheshti University of Medical Sciences. The authors would like to express their appreciation to the many individuals whose cooperation in providing essential information made this effort possible.

\section{References}

[1] A. I. Leshner, "Science-based views of drug addiction and its treatment," The Journal of the American Medical Association, vol. 282, no. 14, pp. 1314-1316, 1999.

[2] R. A. Wise, "Addiction becomes a brain disease," Neuron, vol. 26, no. 1, pp. 27-33, 2000.

[3] L. Niu, B. Cao, H. Zhu et al., "Impaired in vivo synaptic plasticity in dentate gyrus and spatial memory in juvenile rats induced by prenatal morphine exposure," Hippocampus, vol. 19, no. 7, pp. 649-657, 2009.

[4] A. A. Alcantara, H. Y. Lim, C. E. Floyd et al., "Cocaine- and morphine-induced synaptic plasticity in the nucleus accumbens," Synapse, vol. 65, no. 4, pp. 309-320, 2011.

[5] W. Ovtscharoff Jr., M. Segal, M. Goldin et al., "Electron microscopic 3D-reconstruction of dendritic spines in cultured hippocampal neurons undergoing synaptic plasticity," Developmental Neurobiology, vol. 68, no. 7, pp. 870-876, 2008.

[6] A. M. Thompson, B. A. Gosnell, and J. J. Wagner, "Enhancement of long-term potentiation in the rat hippocampus following cocaine exposure," Neuropharmacology, vol. 42, no. 8, pp. 10391042, 2002

[7] E. J. Nestler, "Total recall-the memory of addiction," Science, vol. 292, no. 5525, pp. 2266-2267, 2001.

[8] A. E. Kelley and K. C. Berridge, "The neuroscience of natural reward: relevance to addiction drugs," Journal of Neuroscience, vol. 22, no. 9, pp. 3306-3311, 2002.

[9] B. J. Everitt and M. E. Wolf, "Psychomotor stimulant addiction: a neural system perspective," Journal of Neuroscience, vol. 22, no. 9, pp. 3312-3320, 2002.

[10] J. A. Kauer and R. C. Malenka, "Synaptic plasticity and addiction," Nature Reviews. Neuroscience, vol. 8, no. 11, pp. 844-858, 2007.

[11] A. J. Eisch, M. Barrot, C. A. Schad, D. W. Self, and E. J. Nestler, "Opiates inhibit neurogenesis in the adult rat hippocampus," Proceedings of the National Academy of Sciences of the United States of America, vol. 97, no. 13, pp. 7579-7584, 2000.

[12] A. Pinto, M. Jankowski, and S. R. Sesack, "Projections from the paraventricular nucleus of the thalamus to the rat prefrontal cortex and nucleus accumbens shell: ultrastructural characteristics and spatial relationships with dopamine afferents," Journal of Comparative Neurology, vol. 459, no. 2, pp. 142-155, 2003.

[13] P. Andersen and A. Figenschou Soleng, "Long-term potentiation and spatial training are both associated with the generation of new excitatory synapses," Brain Research Reviews, vol. 26, no. 2-3, pp. 353-359, 1998.

[14] E. Grzęda and R. J. Wiśniewska, "Differentiations of the effect of NMDA on the spatial learning of rats with 4 and 12 week diabetes mellitus," Acta Neurobiologiae Experimentalis, vol. 68, no. 3, pp. 398-406, 2008.

[15] M. Sazdanović, P. Sazdanović, I. Zivanović-Macuzić et al., "Neurons of human nucleus accumbens," Vojnosanitetski Pregled, vol. 68, no. 8, pp. 655-660, 2011.

[16] S. R. Vorel, X. Liu, R. J. Hayes, J. A. Spector, and E. L. Gardner, "Relapse to cocaine-seeking after hippocampal theta burst stimulation," Science, vol. 292, no. 5519, pp. 1175-1178, 2001.

[17] M.-B. Moser, M. Trommald, and P. Andersen, "An increase in dendritic spine density on hippocampal CA1 pyramidal cells following spatial learning in adult rats suggests the formation of new synapses," Proceedings of the National Academy of Sciences of the United States of America, vol. 91, no. 26, pp. 12673-12675, 1994. 
[18] C. Perez-Cruz, M. W. Nolte, M. M. Van Gaalen et al., "Reduced spine density in specific regions of CA1 pyramidal neurons in two transgenic mouse models of Alzheimer's disease," Journal of Neuroscience, vol. 31, no. 10, pp. 3926-3934, 2011.

[19] L. Pu, G.-B. Bao, N.-J. Xu, L. Ma, and G. Pei, "Hippocampal long-term potentiation is reduced by chronic opiate treatment and can be restored by re-exposure to opiates," Journal of Neuroscience, vol. 22, no. 5, pp. 1914-1921, 2002.

[20] J. D. Berke and S. E. Hyman, "Addiction, dopamine, and the molecular mechanisms of memory," Neuron, vol. 25, no. 3, pp. 515-532, 2000.

[21] A. E. Kelley, "Memory and addiction: shared neural circuitry and molecular mechanisms," Neuron, vol. 44, no. 1, pp. 161-179, 2004.

[22] H. Baharvand, A. Piryaei, R. Rohani, A. Taei, M. H. Heidari, and A. Hosseini, "Ultrastructural comparison of developing mouse embryonic stem cell- and in vivo-derived cardiomyocytes," Cell Biology International, vol. 30, no. 10, pp. 800-807, 2006.

[23] G. Paxinos and C. Watson, The Rat Brain in Stereotaxi Coordinates, Academic Press, 2nd edition, 1986.

[24] J. J. Bozzola and L. D. Russell, Electron Microscopy. Principles and Technique for Biologist, Jones \& Bartlett, 2nd edition, 1999.

[25] T. Pattij, D. Schetters, M. C. W. Janssen, J. Wiskerke, and A. N. M. Schoffelmeer, "Acute effects of morphine on distinct forms of impulsive behavior in rats," Psychopharmacology, vol. 205, no. 3, pp. 489-502, 2009.

[26] S. Connor, P. T. J. Williams, B. Armstrong, T. L. Petit, T. L. Ivanco, and A. C. W. Weeks, "Long-term potentiation is associated with changes in synaptic ultrastructure in the rat neocortex," Synapse, vol. 59, no. 6, pp. 378-382, 2006.

[27] N. I. Medvedev, V. I. Popov, G. Dallérac et al., "Alterations in synaptic curvature in the dentate gyrus following induction of long-term potentiation, long-term depression, and treatment with the N-methyl-d-aspartate receptor antagonist CPP," Neuroscience, vol. 171, no. 2, pp. 390-397, 2010.

[28] T. Suzuki, "Postsynaptic density proteins related to the expression and modulation of synaptic plasticity," Japanese Journal of Psychopharmacology, vol. 16, no. 2, pp. 53-58, 1996.

[29] E. C. Miller, L. Zhang, B. W. Dummer et al., "Differential modulation of drug-induced structural and functional plasticity of dendritic spines," Molecular Pharmacology, vol. 82, no. 2, pp. 333-343, 2012.

[30] J. Peng, M. J. Kim, D. Cheng, D. M. Duong, S. P. Gygi, and M. Sheng, "Semiquantitative proteomic analysis of rat forebrain postsynaptic density fractions by mass spectrometry," The Journal of Biological Chemistry, vol. 279, no. 20, pp. 2100321011, 2004.

[31] B. A. Jordan, B. D. Fernholz, M. Boussac et al., "Identification and verification of novel rodent postsynaptic density proteins," Molecular and Cellular Proteomics, vol. 3, no. 9, pp. 857-871, 2004.

[32] J. A. Morón, N. S. Abul-Husn, R. Rozenfeld, G. Dolios, R. Wang, and L. A. Devi, "Morphine administration alters the profile of hippocampal postsynaptic density-associated proteins: a proteomics study focusing on endocytic proteins," Molecular and Cellular Proteomics, vol. 6, no. 1, pp. 29-42, 2007.

[33] T. Yamauchi, "Molecular constituents and phosphorylationdependent regulation of the post-synaptic density," Mass Spectrometry Reviews, vol. 21, no. 4, pp. 266-286, 2002.

[34] K. W. Li, M. P. Hornshaw, R. C. Van Der Schors et al., "Proteomics analysis of rat brain postsynaptic density: implications of the diverse protein functional groups for the integration of synaptic physiology," The Journal of Biological Chemistry, vol. 279, no. 2, pp. 987-1002, 2004.

[35] G. Phillips, J. Huang, Y. Wang et al., “The presynaptic particle web: ultrastructure, composition, dissolution, and reconstitution," Neuron, vol. 32, no. 1, pp. 63-77, 2001.

[36] K. W. Li, C. R. Jimenez, R. C. van der Schors, M. P. Hornshaw, A. N. M. Schoffelmeer, and A. B. Smit, "Intermittent administration of morphine alters protein expression in rat nucleus accumbens," Proteomics, vol. 6, no. 6, pp. 2003-2008, 2006.

[37] L. Prokai, A. D. Zharikova, and S. M. Stevens Jr., "Effect of chronic morphine exposure on the synaptic plasma-membrane subproteome of rats: a quantitative protein profiling study based on isotope-coded affinity tags and liquid chromatography/mass spectrometry," Journal of Mass Spectrometry, vol. 40, no. 2, pp. 169-175, 2005. 


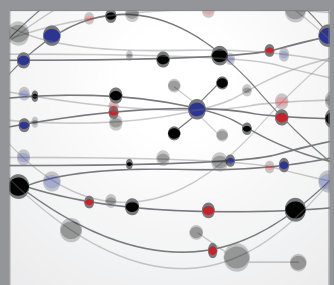

The Scientific World Journal
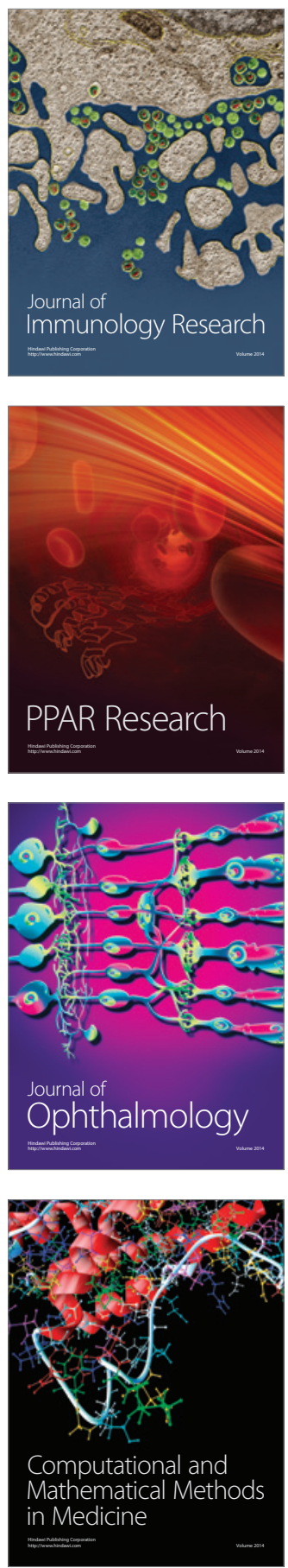

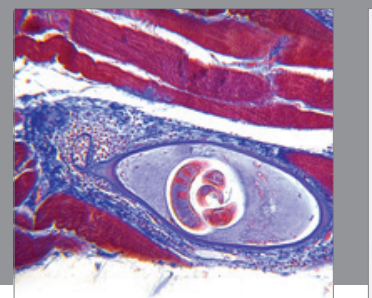

Gastroenterology

Research and Practice
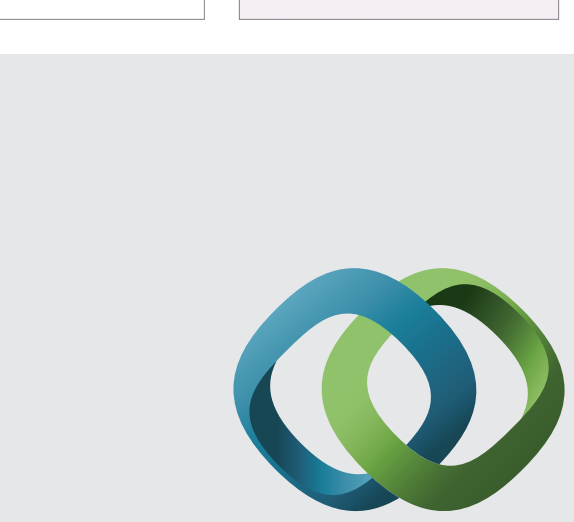

\section{Hindawi}

Submit your manuscripts at

http://www.hindawi.com
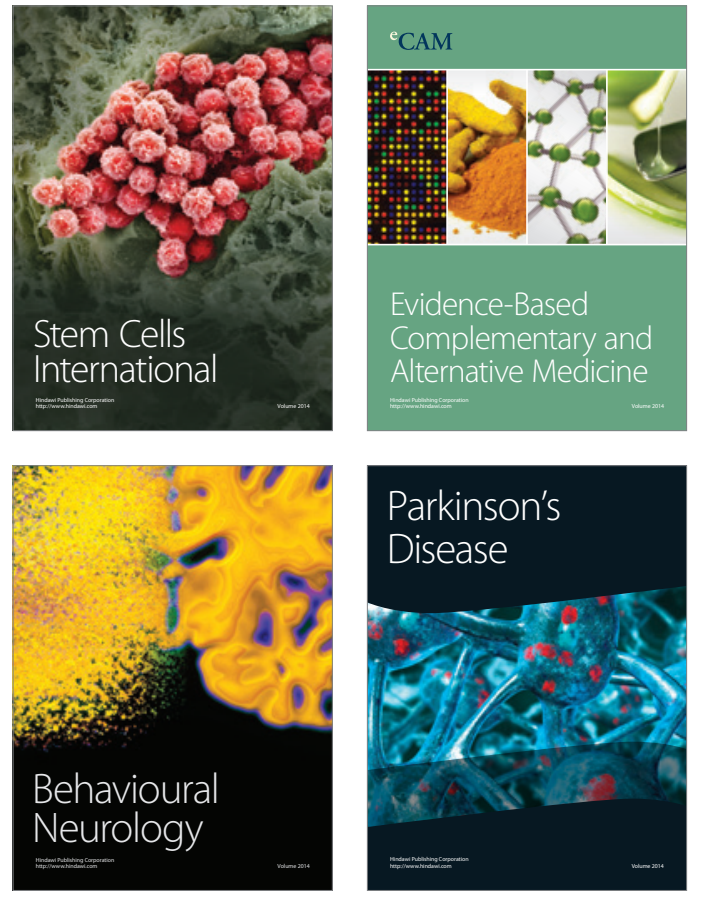
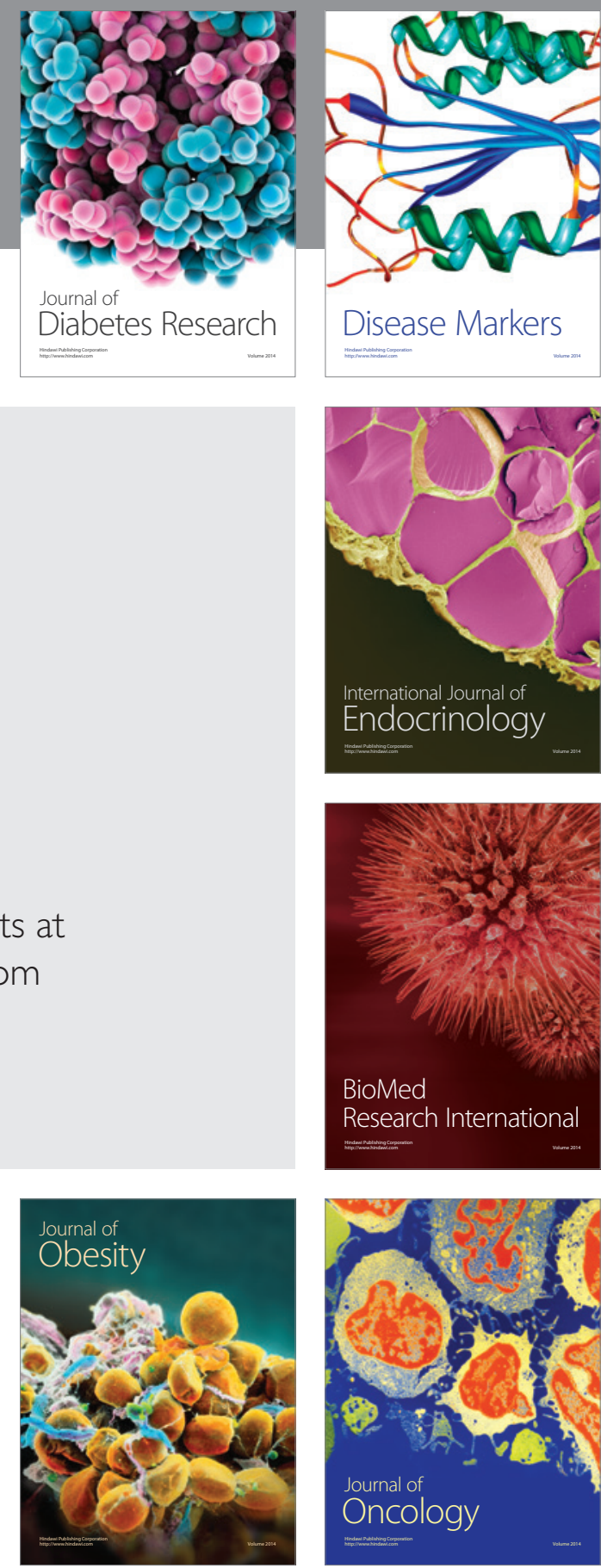

Disease Markers
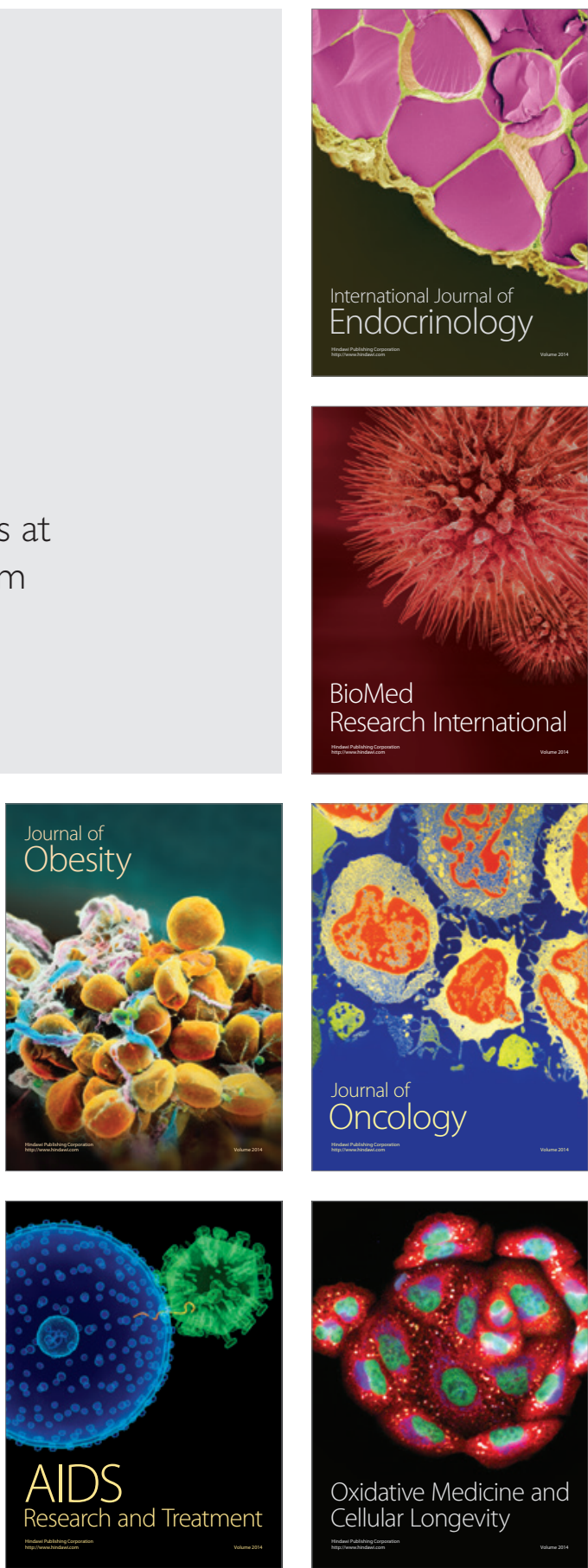